(Shalev RS, Manor O, Auerbach J, Gross-Tsur V. Persistence of developmental dyscalculia: what counts? I Pediatr Sept 1998;133:358-362). (Reprints: Ruth S Shalev MD, Neuropediatric Unit, Shaare Zedek Medical Center, POB 3235, Jerusalem, Israel 91031).

COMMENT. Approximately one half of children diagnosed with developmental dyscalculia in fifth grade are likely to have persistent DC in eighth grade. Division and complex subtraction were especially impaired while addition was generally mastered. Arithmetic problems in siblings were associated with persistent DC in the proband. Educational intervention, provided in $47 \%$ of children with persistent DC compared to only $17 \%$ of those with nonpersistent DC, is apparently not the only answer. The occurrence of associated neurological conditions and components of the Gerstmann syndrome, including dysgraphia, finger agnosia, and R-L disorientation, would have been of interest, and might explain persistence of DC in some cases. Visual-perceptual and spatial disturbance. problems with symbols, language and reading disorders, impaired concepts of direction and time, and memory deficits may be implicated in arithmetic difficulties. A variety of teaching strategies are required in mathematics (Lerner J. Learning Disabilities. 4th ed, Boston, Houghton Mifflin, 1985). Developmental dyscalculia is a chronic disorder that is not outgrown, but demands the same interest of neurologists and educators as dyslexia.

\title{
FRONTAL LOBE INFARCTION AND COGNITIVE DEFICITS
}

Cognitive deficits associated with frontal-lobe infarction in children with sickle cell disease (SCD) were examined at the Institute of Child Health, London, UK. Of 41 with SCD who had MRIs, 5 with stroke symptoms had large frontal lobe (FL) infarcts, and 4 without symptoms had smaller FL infarcts. Those with stroke had significant impairments of IQ memory, and FL function, on the Wisconsin Card Sorting Test (WCST), and those with covert infarction had lesser degrees of cognitive impairment. (Watkins KE, Hewes DKM, Connelly A et al. Cognitive deficits associated with frontal-lobe infarction in children with sickle cell disease. Dev Med Child Neurol 1998;40:536-543). (Respond: KE Watkins MSc, Cognitive Neuroscience Unit, Institute of Child Health, The Wolfson Centre, Mecklenburgh Square, London WC1N 2AP, UK).

COMMENT. Covert infarcts in the frontal lobes may be defined by MRI in $10 \%$ of children with sickle cell anemia. The neurologic examination may be normal but cognitive tests may uncover deficits in IQ memory, and frontal lobe function.

\section{PARATONIA AND FRONTAL LOBE COGNITIVE FUNCTION}

Paratonia, an alteration of tone to passive movement, was assessed in 25 adult patients with degenerative dementia and correlated with other tests of frontal lobe function (echopraxia, distractibility, word fluency) and cognitive function (Mini-Mental State Examination) in a study at Ohio State University Medical Center, Columbus, OH. A modified Kral procedure which measures continued movement after cessation of passive movement (facilitory paratonia) correlated better with a subjective rating of facilitory paratonia than with oppositional paratonia (gegenhalten). The Kral procedure also predicted echopraxia. Both forms of paratonia and the Kral procedure each predicted scores on the MMSE for frontal lobe cognitive function. (Beversdorf DQ Heilman KM. Facilitory paratonia and frontal lobe functioning. Neurology Oct 1998;51:968-971). (Reprints: Dr David Q Beversdorf, Department of Neurology, Ohio State University Medical Center, 1654 Upham Dr, Columbus, OH 43210). 